\title{
ICT and Environmental Sustainability: A Case Study of a Grassroots Initiative
}

\author{
Ana Cardoso and João Carvalho \\ Department of Information Systems, University of Minho \\ Campus de Azúrem, Guimarães, Portugal \\ id2629@alunos.uminho.pt, jac@dsi.uminho.pt
}

\begin{abstract}
Increasingly, local communities develop projects and grassroots initiatives that address climate change and environmental sustainability issues. These projects often commence informally and adopt web-based free information and communication technologies (ICT) applications to support their functioning. ICT applications are used to promote the goals of the project, to recruit more supporters and to facilitate debate among citizens sympathetic to the cause of environmental stewardship. However, as some of these projects evolve they become more complex. Struggling with lack of funding, the solution is to imaginatively combine free web-based ICT applications, to adapt existing open source applications, and even to develop customized solutions. We present the results of an exploratory case study of a grassroots initiative with environmental sustainability goals. The study shows some evidence of innovative practices in the appropriation of ICTs and in the communication campaign. Implications of this research for online communities and society are also discussed.
\end{abstract}

Keywords: Community-based projects, grassroots initiative, case study, ICT applications, innovation, and environmental sustainability.

\section{Introduction}

Lately, more attention has been dedicated to the issues of sustainable development and impact of human activities in the environment. As developing nations became more industrialized and the competition for natural resources increased, concern has shifted from how to induce and sustain economic growth to whether planet Earth can resist the pressing for more natural resources, specially energy, if developing countries achieve the living standards of most people in Europe and North America.

The immediate answer to this concern has been a top-down approach. Indeed, these issues have been discussed in conferences at an international level, for example the United Nations Climate Change Conference, but consensus has been difficult to achieve and progress has been minimal. The foreseeable solution of more taxation based on $\mathrm{CO} 2$ emissions and more state interventionism is controversial and its possible benefits are not unequivocally recognized.

The discussion of solutions at an international level has not hampered the initiative of resolute groups of citizens that have developed community-based projects to

The original version of this chapter was revised, a wrong link has been removed from reference 2 . 
address environmental sustainability concerns and related problems, as for example Let's Do It World [1], Carbon Rally [2], or Transition Network [3]. These grassroots initiatives have gathered a significant support base and are demonstrating that bottomup approaches can effectively complement top-down solutions. This complementarity of top-down and bottom up approaches to address a complex and wicked problem such as climate change has been suggested in the field of information systems [4].

Our working definition of community-based projects with environmental sustainability goals regards these initiatives as organized expressions of voluntary work initiated by citizens in order to benefit the natural environment. In other words, these informal nonprofit projects gather citizens from all societal quadrants that voluntarily contribute with their resources to a joint enterprise that will positively impact the natural environment, as for example cleaning up illegal dumpsites, reforestation of burned areas, monitoring of forests in order to prevent fires, and lifestyle change to reduce individual carbon emissions in ordinary activities.

Sometimes these projects commence after in-person encounters, where the discussion of ideas that will benefit the community and its environment take place, but that is not always the rule. While it is necessary that a founding group of people agree on the merits of an idea for it to materialize into a project, the discussion of ideas can happen in online discussion forums or through exchange of e-mails. Besides, since these projects aim to involve the largest possible number of citizens, the creation of an online community facilitates the engagement of a large number of supporters.

Online communities or virtual communities have been studied in the past for different reasons. For example, in the information systems (IS) area some of the first studies about online communities focused on collaboration in the context of virtual teams, that is teams of people located in different geographical locations, working collaboratively [5], [6]. A review of the literature about virtual community informatics attempted at clarifying the definition of virtual community, and identified commonalities among different definitions, namely the use of computer-mediated spaces and computer-based technology, the focus on communication and interaction, and the building of relationships among its members [7].

Another issue of concern has been the sustainability of online communities in terms of their ability to survive and to hold a steady or increasing number of members. It has been found that membership size is contingent on the availability of resources and on the communication activity provided by the online community [8]. Research in this topic has also explored the motivation of members to contribute knowledge to an online community and the governance of these communities.

More recently, the issue of influence of institutions on online communities has also drawn the attention of researchers [9]. It was found that even though online communities present themselves as open channels for free speech, there are constrained to pure democratic debates because of institutional influences. Moreover, this often results in these communities becoming channels for reproducing institutionalized perspectives instead of facilitating the emergence of democratic debates in social movements [10].

Despite some research on online communities, basic issues as the success or failure of online communities and even agreement on the basic definition of online community remain open. Moreover, a panel of IS experts recently identified the need to 
investigate the management and evolution of community boundaries, "the evolution of community affordances as online communities enact a variety of technological solutions in support of their evolving needs," and also the opportunities and threats resulting from the new relational capabilities enacted by social media software [11].

In this article we describe a case that shows how a community-based project adopted ICTs to support its functioning and discuss the project's results from the point of view of innovation. The rest of the article has the following structure. In Section 2 we explain the research approach and describe the case. Section 3 reports on the results, and we conclude with a discussion of findings and limitations in Section 4.

\section{Methods}

\subsection{Research Approach}

We adopted an exploratory research design because of our interest in the topics of ICT for sustainable development and online communities, which are relatively new and under-investigated phenomena. An exploratory case study design is appropriate for describing and analyzing a new or relatively unstudied phenomenon and it is not required that such an approach tests propositions based on established theory [12], or inductively generates new theory [13]. However, exploratory case studies need to "state their purpose, as well as the criteria by which an exploration will be judged successful" [12]. Thus, we conducted an exploratory case study with the goal of better understanding how community-based projects with pro-environmental goals adopt ICT applications to support their operations and achieve their goals and also to understand how these ICTs contribute to the success of the project.

The purpose of this exploration is to provide insights about these issues and also to refine our future data collection plans for an in-depth case study. Since we already identified some themes for an in-depth analysis, namely the leadership of communitybased projects, the process of evolving an online community into a formal institution, and the creation of intellectual capital within an online community, we will follow this exploratory study with an in-depth interpretive case study.

The selection of cases for our exploratory study was based on the following criteria: we were looking at community-based projects or initiatives with environmental sustainability goals that used web-based ICTs to organize groups of citizens doing volunteer-based work. Moreover, we also applied the criteria of opportunity, that is, we looked first into cases where access could be more easily negotiated. Multiple cases were selected based on these criteria, but the fact that the case we present here was quite unique and could yield richer insights, made its selection more interesting.

Data collection was done from March to November 2011. As this case happened in 2010, was widely promoted online and through mass media, a rich collection of archival data was available. We collected archival data such as minutes of meetings, forms and tutorials, pictures, project documentation, news reports about the project, newspaper articles, and also transcribed four interviews (about 12.800 words). The interviews consisted primarily of open-ended questions, were audio recorded and transcribed. The archival data includes image, text, video and audio files amounting to 
142 files. We acknowledge the limitation in terms of number of interviews and argue that the rich and varied archival sources partially compensate for this.

\subsection{Case Description: Let's Do It Portugal!}

In March 2010, more than 100.000 persons went voluntarily to the Portuguese forests on a rainy day to clean up illegal dumpsites. The preparation of this event started 9 months before, when a group of 3 friends learned about a grassroots initiative that organized a clean-up of Estonia's forests in 2008. This group was inspired by the Estonian project and decided to lead an identical project in Portugal. The project's vision was not the cleaning up itself but, instead, to raise awareness of the problem of illegal dumping of forests and broadcast the message that illegal dumping is not acceptable.

A chain of e-mail messages, inviting people to join a social network website created in the Ning platform triggered an impressive number of 4.000 registrations after only two weeks, and this number grew to more than 30.000 people. Ning (www.ning.com) is a platform to create and host micro social network websites that allow users to interact in similar ways as other popular social sites.

This project involved only donated and lent resources of different types: tools, bags and gloves for collecting trash, use of technical equipment, trucks and tractors, free public transportation for volunteers, and volunteer workforce - from cleaning to coordination and management tasks. In fact, one of the guidelines of the project specifically stated that no monetary donations could be accepted, only donations of goods and services.

The organization of the project was decentralized across districts and municipalities. A leading group took the national coordination. It included the founders, plus 20 district coordinators together with 3 coordinators for the environmental, legal and technological areas. District coordinators were volunteers that lead the project in their districts with the help of municipal teams of volunteers and municipal authorities. Technical coordinators offered their expertise in key areas for the smooth progress of the project.

All volunteers were invited to in-person monthly meetings. The purpose of these meetings was to engage a large number of possible volunteers, to promote the project and to explain to volunteers what needed to be done and how. In order to create a coordinated and integrated effort, the national coordination issued broad guidelines about how to proceed and published them in the projects' website.

Each coordination unit decided how to enact those guidelines and autonomously identified their cleaning needs and defined their goals. This involved locating and characterizing the illegal dumpsites in each municipality, finding sponsors to provide the necessary material resources, recruiting volunteers for the cleaning day, signing protocols with environmental services companies that received the collected trash, and rehearsing the logistics of a one-day cleaning event with a small group of volunteers, usually children, that cleaned up a public space.

The national coordination sought collaboration and support of various online communities related with outdoors activities in forests, namely the forum of 
all-terrain vehicle owners and drivers, cyclists, and the growing online communities of geocachers - a modern form of treasure hunt for recreational purposes. They also involved public and private schools, Scouts groups, and signed protocols with the military, the civil protection, private companies, municipalities and parishes.

The project developed a bottom-up communication strategy with chains of e-mails and social networking websites. Later, local media such as radio and newspapers helped promote it, and it grew steadily during six months. In the final three months, it drew attention of national television channels and newspapers, especially because the president of the Portuguese Republic was appointed as the honorary sponsor of the project.

For the discovery and characterization of the dumpsites, the project adopted an open approach for both the way of doing it and the technology to support it. Following a crowd source procedure, any volunteer could report the existence of a dumpsite and its characteristics (e.g. size, composition). The report of a dumpsite included its GPS coordinates, a textual description of the type of trash (e.g. furniture, tires, domestic appliances, etc) and pictures. These data were inserted in a web-based platform, thus enabling the creation of a map of illegal dumpsites and facilitating the estimation of the necessary material resources for the clean-up.

Hence, in the cleaning day there were 11.000 illegal dumpsites inserted in the database of this web-based platform. Local coordination teams retrieved information about the dumpsites in their municipalities and assigned cleaning tasks to teams of volunteers that showed up at previously defined meeting points. At the end of the day, more than 50 tons of illegal wastes were removed from the forests. Both the volunteers and the general public were surprised with the results of the project, especially with the high figures of volunteer participation and impressive quantity of waste removed.

\section{$3 \quad$ Results}

This project was very ambitious in terms of its goals: cleaning all the country's forests in one single day. To obtain the necessary resources and to mobilize a very large number of volunteer citizens was a great challenge. In fact, their dependency on donated resources and voluntary workers posed threats to the project's success. To cope with their self-imposed limitations, they used several free web-based ICT applications to broadcast the project's goal and to gather a supporting base of volunteers. This was a fundamental first step for the development of working teams that prepared the cleaning day locally.

The initial broadcasting strategy also reached mass media and facilitated access to inexpensive promotion time and space on mass media through interviews with project members, news pieces, and sponsorship of free advertising time. This made possible the connection of the online world with the offline world, and thus increased the supporting base of volunteers and sponsors.

In Table 1 we summarize the different ICTs adopted by the project and relate them to the project needs. The data for drawing this table was gathered from the project 
documentation. In the following sections, we discuss how the adoption of ICT was phased throughout the project.

Table 1. Project needs and ICTs adopted by the project

\begin{tabular}{|c|c|c|}
\hline Project Needs & ICTs adopted & Category \\
\hline $\begin{array}{l}\text { Have a webpage where all relevant information } \\
\text { about the project is available }\end{array}$ & Joomla & Communication \\
\hline Report the progress of local teams & Wordpress, Blogger & Communication \\
\hline $\begin{array}{l}\text { Advertize and broadcast information about the } \\
\text { events of the project at national level }\end{array}$ & $\begin{array}{l}\text { E-mail chains } \\
\text { Facebook; Twitter }\end{array}$ & Communication \\
\hline Extend social circles of the project & $\begin{array}{l}\text { Facebook page; Hi5; } \\
\text { LinkedIn Group }\end{array}$ & Communication \\
\hline Organize working teams across the country & Ning & Team management \\
\hline Manage mailing lists for coordination units & Google groups & Team management \\
\hline Collaborative writing of project documentation & $\begin{array}{l}\text { Google Docs } \\
\text { Dropbox }\end{array}$ & Operations \\
\hline Registration of volunteers & $\begin{array}{l}\text { Google } \\
\text { (forms) }\end{array}$ & Operations \\
\hline $\begin{array}{l}\text { Map the location and characterize illegal dump- } \\
\text { sites }\end{array}$ & $\begin{array}{l}3^{\text {rd }} \text { Block; LimparPt } \\
\text { Wikiloc; Wikimapia }\end{array}$ & Operations \\
\hline
\end{tabular}

\subsection{Improvisation Stage: July to November 2009}

The project's kick-off happened in July 2009, nine months before the cleaning day, which was 20 March 2010. At the time, the likely date for the cleaning day was the end of October, which was three months after the project's inception. However, in September, when the first meeting of national coordination took place, the date of 20 March was chosen instead because it overlapped with public school vacations, allowed more time for the preparative work of mapping the trash across the country, had a higher likelihood of good weather, and was also symbolic in terms of transition from Winter to Spring time.

In these first months, the set up of supporting ICTs and platforms involved some improvisation, based on the experience and knowledge of project members, as the following quotation of a project member shows:

"We need a site that describes the project. There, we can insert information about the project and link it to other project-related sites, as for example Ning and Wikiloc. I do not know how to build a website from scratch but have some experience with Joomla, a content management system, and can give it a try." 
Another example is the communication and promotion strategy. In a first stage of the project, national coordinators contacted friends and acquaintances via email. Then, they sought the cooperation of online communities related with outdoor activities such as drivers of all terrain vehicles, mountain bikers, hikers, geocachers, hunters and fishers. As one project member explained about emailing a standard message about the project:

"In this phase the important [task] is to spread the word. I know someone from the community $X$ and you know someone from the community $Y$, that in turn also knows someone from [the community] B, and so on... In a month, if all goes well, [our message] will reach the whole country."

Social networking websites were also explored as communication tools. They created a group in LinkedIn, a page and a profile in Facebook, a Twitter account, a profile and a page in Hi5. These groups and pages were used to convey information about the project but also enabled the creation of a web presence, which was important for the project to connect with volunteers. Some local groups also created their Facebook groups and pages. It is interesting to notice that the web presence through groups and pages had different impacts. For example, the Facebook page of the project has more than 4.000 fans and continues to be active to date. On the other hand, the LinkedIn group of only 122 members had little activity before the cleaning event and is not active anymore.

We can also recognize improvisation in the choice of ICTs to support the task of creating a map of the trash existent in the Portuguese forests. In the first months, the project leaders explored free web-based ICT applications that allowed the creation of points of interest in Google Maps or Google Earth. As one project member explains:

"I think it should be possible to create a database and then insert [the data] in Google Earth. Or even better, we can create the waypoints directly in Google Earth and assign a code to describe them. (...) The possibility of using Wikiloc also seems viable especially because [another member] is very experienced with it. Linked with the waypoint there should also be a photo so that we can see the quantity and type of trash to be removed."

They also tried Wikimapia, another free web-based ICT application, as a project member explains:

"Following the suggestion of a friend from Ning (...), I created an account in Wikimapia. Wikimapia is more interesting for this project than Wikiloc because we can visualize an entire area with the registered waypoints. I think it facilitates the mapping [of dumpsites] because there are many persons who know where the dumpsites are but who do not have a GPS. Thus, they can locate the place in Google Earth and send an e-mail with the coordinates or with a print screen to the project team." 
However, none of these solutions were satisfactory and were abandoned when the developers of $3^{\text {rd }}$ Block, a geo-referencing web-based platform with some social features, approached the national coordinators and suggested the use of their software.

\subsection{ICT Customization and Innovation: November 2009 to March 2010}

After some time improvising with Wikiloc and Wikimapia, it was becoming clearer that these web-based ICT applications did not address the project needs. Wikiloc is a web-based ICT application that allows users to upload and share trails based on their GPS tracks. On the other hand, the goal of Wikimapia is to "create and maintain a free, complete, multilingual, up-to-date map of the whole world." Wikimapia combines Google Maps with a wiki system and allows users to add information, in the form of a note, to any location on Earth. Therefore, it is more flexible than Wikiloc in terms of how it can be utilized, but the GPS capabilities are not as good as Wikiloc, as this functionality only works in Windows systems and it cannot articulate fully with GPS devices.

When the developers of $3^{\text {rd }}$ Block learned about the project, they had already developed a web-based platform that allowed users to locate places of interest in a map. This platform was very flexible and could be used in different ways, as for example to build an ICT application for selling properties without the need of intermediaries. At the time, 3rd Block team noticed the project had problems in terms of management of dumpsites' locations and they wanted to test their prototype, as they explain:

"We noticed that the project had some problems at the level of management of trash locations and we had a platform ready to be tested that could be used for that. So, we needed users to test our software and they needed a software tool but, given the national scale of the project, they had much more to do [than build a software tool]. So, we presented them what we had done and explained what could be done on top of that, and from that moment on we worked together for the success of the project."

An innovative feature of $3^{\text {rd }}$ Block is the crowd sourcing of information. In other words, any person can register as a user and insert information about a particular site. For this reason, $3^{\text {rd }}$ Block was appropriate for the task of mapping and characterizing dumpsites, which was done by volunteers.

The platform $3^{\text {rd }}$ Block had been designed to support the work of a "manager of geographical areas", as for example the team of a city council who is responsible for the management of public spaces in the municipality. As such, $3^{\text {rd }}$ Block allowed the citizens of a council to report positive and negative aspects found in these public areas so that the manager of that area could quickly identify problems, resolve them and provide feedback about them.

Hence, developers of $3^{\text {rd }}$ Block platform built a web-based ICT application that likened the role of the manager of geographical areas to the national and district coordinators, and the role of the citizens to the volunteers that located dumpsites in the forests. The mapping of trash points required a GPS device and, if possible, a digital 
camera. Equipped with these devices and with a paper form, the volunteers went to the forests and collected data to insert later in $3^{\text {rd }}$ Block.

In order to automate the process of data collection about dumpsites, an independent programmer later developed an ICT application that allowed volunteers to collect data with the GPS and the camera incorporated in their smart phones and to send it automatically to $3^{\text {rd }}$ Block. This made data collection easier and also minimized user created data mistakes.

\section{Discussion}

In this article we report on a case study of a nationwide project of cleaning up illegal dumpsites in Portuguese forests on a single day. This case is exemplary in terms of how ICT is appropriated as a tool for civic participation and demonstrates that citizens are ever more capable of using ICT devices and applications to organize grassroots initiatives that have impact. However, this case study has its limitations. First, even though this project is a replication of the original one-day clean up of Estonian forests, the findings are idiosyncratic to the Portuguese context and thus are not generalizable. Second, we reiterate that data collection focused mostly on archival data and that a following in-depth study will therefore capitalize on interviews of volunteers having different roles in this project.

We identify two innovative outcomes of this project. The first is the development of ICT applications, both for smart phone and web-based, to collect data about dumpsites and to create a map of existing trash in the forests. Even though the quick development of software had benefited from the existence of a generic platform ( $3^{\text {rd }}$ Block) for geo-mapping locations of interest, it was this nationwide project that made possible the testing and improvement of that platform. Indeed, incremental changes of $3^{\text {rd }}$ Block were made after suggestions of project's members and detection of software errors.

Another innovation is the communication strategy. This project demonstrates that a communication campaign can be done with no prior funding and no monetary donations. In fact, it was possible to mobilize about 100.000 people that voluntarily removed 50 tons of trash from the forests on a single day with only donated or borrowed resources (material goods and services). The communication campaign commenced with e-mail chains and word of mouth, evolved to social networks, and then interested local mass media, who provided free advertising time and space (e.g. one-minute radio spots, reports and interviews in local radios and local newspapers). Finally, it reached national mass media, where it had some prime time in the daily news.

Additionally, we recognize implications of ICTs and social media for society in this case. ICTs can build a "big picture", as for example the map of dumpsites in the country and, on the other hand, social media fosters the adoption of a collaborative paradigm because it facilitates connectedness, communication and coordination. Thus, citizens are nowadays more empowered to actively participate in their community and to co-create projects and grassroots initiatives because they understand that small efforts, if coordinated, can have large impact. 
In terms of online communities, there are insights on how an online community commences and evolves. Three factors played an important role in growing this online community: the creation of web presence from an early stage, the involvement of other online communities with common interests, and the conspicuous communication of a very simple and consistent message. Although the Ning website had been deactivated last year due to lack of activity after the clean-up day, there remains a group of more than 5.000 persons in Facebook that follows the updates of this project.

Acknowledgments. We acknowledge support of FCT via Bolsa de Doutoramento SFRH/BD/60838/2009 and support of Fundos Feder - COMPETE and FCT via FCOMP-01-0124-FEDER022674. We are grateful to the informants of the case discussed in this paper for providing the information upon which this case is based.

\section{References}

1. Let's Do It: Let's Do It World!, http: / / www . letsdoitworld.org/

2. Carbon Rally: Carbon Rally

3. Transition Network: Transition Network, http: / /www.transitionnetwork.org/

4. Hasan, H., Dwyer, C.: Was the Copenhagen Summit doomed from the start? Some insights from green IS research. In: Proceedings of Americas Conference on Information Systems 2010, Lima, paper 67 (2010)

5. Jarvenpaa, S., Leidner, D.: Communication and trust in global virtual teams. Organization Science 10, 791-815 (1999)

6. Jarvenpaa, S., Knoll, K., Leidner, D.: Is anybody out there? Antecedents of trust in global virtual teams. Journal of Management Information Systems 14, 29-62 (1998)

7. Lee, F.S.L., Vogel, D., Limayen, M.: Virtual community informatics: a review and research agenda. Journal of Information Technology Theory and Application (JITTA) 5, 47$61(2003)$

8. Butler, B.S.: Membership size, communication activity, and sustainability: a resourcebased model of online social structures. Information Systems Research 12, 346-362 (2001)

9. Hercheui, M.D.: A literature review of virtual communities. Information, Communication and Society 14, 1-23 (2011)

10. Hercheui, M.D.: Virtual communities and democratic debates: a case study on institutional influences. In: ICIS 2009 Proceedings, paper 118 (2009)

11. Johnson, S.L., Butler, B., Faraj, S., Jarvenpaa, S., Kane, G.: New directions in online community research. In: ICIS 2010 Proceedings, paper 173 (2010)

12. Yin, R.K.: Case Study Research: Design and Methods. Sage, Thousand Oaks (2009)

13. Eisenhardt, K.M.: Building theory from case study research. The Academy of Management Review 14, 532-550 (1989) 